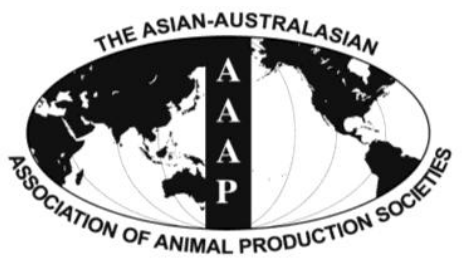

Asian-Aust. J. Anim. Sci.

Vol. 26, No. 3 : 303-308 March 2013

http://dx.doi.org/10.5713/ajas.2012.12413

www.ajas.info

pISSN 1011-2367 elSSN 1976-5517

\title{
Subfertility Problems Leading to Disposal of Breeding Bulls
}

\author{
Marzina Khatun, Simarjeet Kaur, Kanchan and C. S. Mukhopadhyay ${ }^{1, *}$ \\ Department of Animal Genetics and Breeding, GADVASU, Ludhiana, Punjab-141004 India
}

\begin{abstract}
Subfertility problems are encountered frequently in the cattle and buffalo bulls commercially maintained for semen production in dairy farms and under field conditions for natural insemination. Reports are scarce on the incidence of subfertility in breeding bulls, especially in India. The objective of the present study was to assess the incidence of the male reproductive anomalies leading to disposal of bovine bulls at GADVASU dairy farm, Ludhiana, Punjab (India). Data on frequency of various subfertility and disposal pattern of bulls maintained at the dairy farm, GADVASU, were collected for $12 \mathrm{yrs}$ (1999 to 2010) and compiled from different record registers. Percentage of bulls that produced freezable semen (out of reserved ones) was less in cattle (25.641\%) as compared to that of buffalo (30.4\%). Various subfertility traits like poor libido and unacceptable seminal profile were found to be the significant reasons $(\mathrm{p}<0.01)$ for culling of the breeding bulls. Inadequate sex drive and poor semen quality were the main contributing factors for bull disposal in cattle whereas poor semen freezability was most frequently observed in buffalo bulls. All the male reproductive traits were significantly different $(\mathrm{p}<0.05)$ for the periods of birth, except for semen volume, initial motility (IM), age at last semen collection (ALSC) and age at disposal. The ages at first and last semen collection as well as freezing (i.e. AFSC, ALSC and AFSF, ALSF, respectively) and age at disposal (AD) were higher in buffalo. The spermatological parameters and semen production period (SPP) were higher in cattle. The age at first semen donation and breeding period could be reduced by introducing the bulls to training at an early age. The results revealed an increasing trend in individual motility (IM) while semen volume, AFSC, AFSF, AD, FSPP, SPP, ALSC and ALSF showed a decreasing, however, not a definite trend, over the periods. The semen donation traits like, AFSF, of the cattle and buffalo bulls could be predicted from the AFSC, using prediction equation derived in the present study. (Key Words: Bull Disposal, Subfertility, Semen Quality, Semen Freezability, Prediction Equation)
\end{abstract}

\section{INTRODUCTION}

Bulls, considered as the half of the herd, are selected at an early age as future breeding bulls. However, a considerable number of male animals are culled at various stages of life due to limited growth and reproductive potentialities. The subfertility problems in bulls, like inadequate libido and poor seminal profile, may be accredited due to genetic, environmental and managemental causes. The production traits in animals are mainly genetic in nature; however, reproduction parameters are more influenced by environment (Mukhopadhyay et al., 2010). The optimum serving capacity and seminal profile are the crucial parameters to assess the breeding soundness of bovine bulls. Genes responsible for sex-drive, spermatogonial proliferation and differentiation, sperm

\footnotetext{
* Corresponding Author: C. S. Mukhopadhyay. Tel: +91-161-241 4023, Fax: +91-161-2400822, E-mail: csmukherjee@ gmail.com

1 School of Animal Biotechnology, GADVASU, Ludhiana, Punjab-141004, India

Submitted Aug 2, 2012; Accepted Oct. 31, 2012; Revised Nov. 24, 2012
}

cytoskeleton structure, membrane structure and integrity, sperm viability etc. are being identified and studied to shed light on the aforementioned problems. Two species were taken under investigation i.e. cattle and buffalo. The Holstein- Friesian crossbred cattle and purebred Murrah buffalo bulls were reared at the Dairy Farm; Guru Angad Dev Veterinary and Animal Science University, Ludhiana, in loose housing system in individual bull pens, under stall fed condition and uniform managemental practices. The present investigation was designed to investigate the incidence of subfertility traits leading to culling of dairy bulls and to study the factors like, species/breeds, season of birth and period of birth affecting the male reproductive parameters. The male reproduction parameters have also been predicted using linear regression model with age at first semen collection as the predictor variable.

\section{MATERIALS AND METHODS}

\section{Collection of data}

Data on various semen parameters (semen volume and 
initial motility), reproduction parameters and the causes of disposal of HF-crossbred cattle and Murrah buffalo bulls, during the period of 1999 to 2010 , were compiled from the available calving records, daily semen collection register, auction lists and the performance record-registers (GADVASU Dairy Farm). Data on male reproductive traits were available for a total of 129 bulls. Animals which are under experimental trials and those with incomplete records were not included in the study as it adds to the effect of different genetic and non-genetic factors on the fertility parameters. The semen production parameters, generated from the primary data, includes: age at first semen collection (AFSC), age at first semen freezing (AFSF), semen production period (SPP), frozen semen production period (FSPP), age at last semen collection (ALSC), age at last semen freezing (ALSF) and age at disposal (AD). The subfertility traits included poor libido, poor semen quality (initial motility <45\%) and poor semen freezability (post thaw motility $<35 \%$ ) which lead to disposal of bulls.

\section{Statistical analysis}

To study the effect of species (cattle and buffalo), the period vis-à-vis the season of birth the data generated on male specific breeding soundness traits were subjected to least squares analysis. Seasons of birth were further divided into four categories: summer (May to July); rainy (August to October); winter (November to February) and spring (March to April). The periods of semen donation were taken as six years interval, 1985 to $1990 ; 1991$ to $1996 ; 1997$ to 2002 and last eight years i.e. from 2003 to 2010 , corresponding to the subsequent changes in the managemental practices. The least squares model that incorporated the fixed effects (of species, birth period and birth season) is : $\mathrm{Y}_{\mathrm{ijkl}}=\mu+\mathrm{Sp}_{\mathrm{i}}+\mathrm{S}_{\mathrm{j}}+\mathrm{P}_{\mathrm{k}}+\mathrm{I}_{\mathrm{Sp} . \mathrm{P}}+\mathrm{e}_{\mathrm{ijkl}}$; where, $\mathrm{Y}_{\mathrm{ijk}}$ $=$ character variable of $\mathrm{l}^{\text {th }}$ bull under $\mathrm{i}^{\text {th }}$ species, $\mathrm{j}^{\text {th }}$ season of birth and $\mathrm{k}^{\text {th }}$ period of birth; $\mu=$ population mean; $\mathrm{Sp}_{\mathrm{i}}=$ fixed effect of $i^{\text {th }}$ species $(i=1,2) ; S_{j}=$ fixed effect of season of birth $(j=1,2 \ldots 4) ; P_{k}=$ fixed effect of $k^{\text {th }}$ period of birth $(\mathrm{k}=1,2 \ldots 4) ; \mathrm{I}_{\text {Sp.P. }}=$ effect of interaction between species and period; $\mathrm{e}_{\mathrm{ijkl}}=$ random error for $\mathrm{l}^{\text {th }}$ observation under $\mathrm{i}^{\text {th }}$ species, $\mathrm{j}^{\text {th }}$ season and $\mathrm{k}^{\text {th }}$ period of birth.

Chi-square test was done for the test of heterogeneity (Snedecor and Cochran, 1994) between the species for different subfertility traits. The statistical software used for data analysis was SPSS 11.

Linear regression equation has been constructed to predict the semen donation parameters (AFSF, AD, SPP, FSPP) using the age at first semen collection as predictor variable. The regression equation constructed separately for each of the species, for prediction of the andrological parameters is: $\mathrm{Y}_{\mathrm{i}}=\mathrm{b}_{0}+\mathrm{b}_{1} * \mathrm{X}_{\mathrm{i}}+\mathrm{e}_{\mathrm{i}}$; where, $\mathrm{Y}_{\mathrm{i}}=$ dependent variable of $i^{\text {th }}$ observation; $b_{o}=$ intercept constant; $b_{1}=$ regression coefficient; $\quad e_{i}=$ random error for $i^{\text {th }}$
Table 1. Detail of male calves born and reserved for freezable semen production

\begin{tabular}{lcc}
\hline Particulars & Cattle & Buffalo \\
\hline Total born & 414 & 457 \\
Reserved & 273 & 250 \\
Died (among reserved) & 8 & 15 \\
Percentage of bulls reserved & 65.94 & 54.70 \\
Produced semen & 127 & 120 \\
$\begin{array}{l}\text { Bulls produced freezable semen out } \\
\text { of semen producing bulls }\end{array}$ & 70 & 76 \\
$\begin{array}{l}\text { \% of bulls produced freezable semen } \\
\text { (of reserved) }\end{array}$ & 25.64 & 30.40 \\
\hline
\end{tabular}

observation and $\mathrm{X}_{\mathrm{i}}=$ explanatory variable.

\section{RESULTS}

\section{Production of freezable semen}

The total number of cattle and buffalo bulls reserved for breeding and number of bulls produced freezable semen, during the period of 1999 to 2010 has been represented in Table 1. Percent production of freezable semen out of the total number of semen-donating bulls was higher in buffalo $(30.4 \%)$ than in cattle $(25.641 \%)$. The number of bulls producing freezable and non-freezable semen differed significantly $(\mathrm{p}<0.01)$ between the two species (Table 2$)$.

\section{Occurrence of subfertility}

The subfertility traits leading to the disposal of dairy bulls maintained at the dairy farm, GADVASU, has been tabulated in Table 3. Lack of libido, poor semen quality and freezability were the important reasons for the bull wastage both in cattle (26.70\%) and buffalo (25.84\%). One cryptorchid (FC 1367) and two bulls with penile deviation were encountered in cattle during the tenure. Disposal pattern of the bulls showed that poor growth rate was specific to cattle. Chi-square test revealed that the subfertility traits were significantly important reasons $(p<0.01)$ leading to disposal of bulls (Table 4).

\section{Effect of genetic and non-genetic factors on male reproductive parameters}

Least squares analyses of the andrological parameters revealed that species $(\mathrm{Sp})$ and periods of birth $(\mathrm{P})$ had significant effect on most of the traits studied (Table 5). The

Table 2. Test of heterogeneity (chi-square test) to estimate the effect of breed on semen freezability

\begin{tabular}{lcccc}
\hline Particulars & Cattle & Buffalo & $\begin{array}{c}\text { Chi square } \\
\text { value }\end{array}$ & $\mathrm{p}^{*}$ \\
\hline Freezable Semen & 70 & 76 & & \\
Non- freezable semen & 57 & 44 & 0.845 & 0.037 \\
Total & 127 & 120 & & \\
\hline
\end{tabular}

$* \mathrm{p}=$ Probability value at 2 degrees of freedom. 
Table 3. Incidence of subfertility leading to disposal of bulls due to subfertility problems

\begin{tabular}{lrr}
\hline Particulars & \multicolumn{1}{c}{ Cattle } & \multicolumn{1}{c}{ Buffalo } \\
\hline Poor libido (PL) & $8(2.93)$ & $5(2.00)$ \\
Poor semen quality (PSQ) & $16(5.86)$ & $12(4.80)$ \\
Poor semen freezability (PSF) & $7(2.56)$ & $17(6.80)$ \\
Cryptorchid & $1(0.36)$ & $0(0.00)$ \\
Penile deviation & $2(1.40)$ & $0(0.00)$ \\
Bulls culled due to reasons & $33(12.08)$ & $11(4.40)$ \\
$\quad$ & & \\
other than subfertility problems & $20(7.33)$ & $28(11.20)$ \\
Bulls culled due to subfertility & $34(13.19)$ & $34(14.00)$ \\
Total bulls culled & $87(32.60)$ & $73(29.60)$ \\
\% Bulls culled due to sub-fertility & 13.18 & 14.00 \\
$\quad$ (of total reserved from semen produced) & & \\
* Data in bracket represents value in percentage. & & \\
\end{tabular}

Table 4. Chi-square test to study the effect of subfertility problems on disposal of bulls

\begin{tabular}{|c|c|c|c|c|}
\hline Particulars & Cattle & Buffalo & $\begin{array}{l}\text { Chi square } \\
\text { value }\end{array}$ & $\mathrm{p}^{*}$ \\
\hline Subfertility problems & 34 & 31 & & \\
\hline $\begin{array}{l}\text { Other reasons (other than } \\
\text { subfertility problems) }\end{array}$ & 33 & 11 & 0.999 & $2.87 \mathrm{E}-11$ \\
\hline Total culled & 45 & 64 & & \\
\hline
\end{tabular}

$* \mathrm{p}=$ Probability value at 2 degrees of freedom.

effect of season is both direct and indirect. It affects the animal directly through macro and micro climatic factors, which are the temperature, humidity, rainfall and photoperiod. Indirectly it acts by affecting the vegetation, forage quality and soil-plant-animal interaction. The least squares mean along with standard error of the species/breeds for different variables have been given in Table 6 . In cattle, semen volume (S.Vol) was higher than buffalo. While age at first semen collection (AFSC), age at first semen freezing (AFSF), age at disposal (AD), age at last semen collection

(ALSC), freezable semen production period (FSPP) and semen production period (SPP), initial motility (IM) and age at last semen freezing (ALSF) was higher in buffalo. The least squares means of all the reproductive parameters except for initial motility were showing a decreasing yet drifting trend over the periods (Table 7).
Table 6. Least squares mean \pm SE for semen volume, age at disposal, age at first semen collection, age at first semen freezing, frozen semen production period, semen production period, age at last semen collection, age at last semen freezing and initial motility for cattle and buffalo bulls

\begin{tabular}{lcc}
\hline Particulars & Cattle & Buffalo \\
\hline Semen volume & $5.81^{\mathrm{NS}} \pm 0.176$ & $5.50^{\mathrm{NS}} \pm 0.176$ \\
AFSC & $908.1^{\mathrm{a}} \pm 38.5$ & $1,113.7^{\mathrm{b}} \pm 41.5$ \\
AFSF & $1,123.9^{\mathrm{a}} \pm 45.3$ & $1,198.1^{\mathrm{b}} \pm 48.8$ \\
FSPP & $1,074.2^{\mathrm{a}} \pm 51.8$ & $226.9^{\mathrm{b}} \pm 56.9$ \\
SPP & $1,167.1^{\mathrm{a}} \pm 83.3$ & $1,043.2^{\mathrm{b}} \pm 91.5$ \\
AD & $2,231.8^{\mathrm{a}} \pm 94.7$ & $2,458.8^{\mathrm{b}} \pm 104.1$ \\
ALSC & $2,083.1^{\mathrm{a}} \pm 91.2$ & $2,229.0^{\mathrm{b}} \pm 100.3$ \\
ALSF & $2,131.9^{\mathrm{a}} \pm 90.5$ & $2,236.8^{\mathrm{b}} \pm 99.5$ \\
Initial motility & $63.1^{\mathrm{NS}} \pm 0.1$ & $68.1^{\mathrm{NS}} \pm 0.1$
\end{tabular}

S. Vol. = Semen volume (ml); AFSC = Age at first semen collection (d); AFSF $=$ Age at first semen freezing (d); FSPP $=$ Frozen semen production period (d); SPP = Semen production period (d); AD = Age at disposal (d); $\mathrm{ALSC}=$ Age at last semen collection $(\mathrm{d})$ and $\mathrm{ALSF}=$ Age at last semen freezing (d).

${ }_{a, b}$ Rows with no common superscript indicates non-significant difference between the values $(\mathrm{p}<0.05)$.

NS $=$ Not significant.

\section{Prediction of semen production parameters}

The prediction equation for the parameters, namely, SPP, AFSF, AD and FSPP using AFSC as the predictor variable, were significant $(\mathrm{p}<0.01)$ in cattle (Table 8$)$, however, in buffalo only the AFSF was found to be significant $(\mathrm{p}<0.01)$ as the dependent variable (Table 9). The coefficient of determination $\left(\mathrm{R}^{2}\right)$ value was $50 \%$ or more for prediction of $\operatorname{AFSF}(64.5 \%)$ and $\mathrm{AD}(57.9 \%)$ in cattle, vis-à-vis AFSF $(49.9 \%)$ in buffalo, using AFSC as the predictor variable.

\section{DISCUSSION}

\section{Production of freezable semen}

Selection of male calves based on expected predicted difference (EPD) has led to higher culling rate in cattle followed by buffalo due to differences in respective herdsize in GADVASU dairy farm. The increasing use of EPD information by beef cattle producers has placed greater

Table 5. Degrees of freedom (Df) and Mean-Squares values of the effects for various reproductive traits of dairy bulls obtained through least squares analyses of variance

\begin{tabular}{lcccccccccc}
\hline SV & Df & S. Vol. & AD $\left(\times 10^{5}\right)$ & AFSC $\left(\times 10^{5}\right)$ & AFSF $\left(\times 10^{5}\right)$ & ALSC $\left(\times 10^{5}\right)$ & ALSF $\left(\times 10^{5}\right)$ & SPP $\left(\times 10^{5}\right)$ & FSPP $\left(\times 10^{5}\right)$ & IM \\
\hline Sp & 1 & 1.922 & 10.69 & $9.00^{*}$ & 1.17 & 4.41 & 2.28 & 3.18 & $148.92^{*}$ & 0.12 \\
Season (S) & 3 & 1.798 & $1.56^{*}$ & 0.40 & 0.60 & $1.87^{*}$ & 1.42 & 3.42 & 1.33 & 19.34 \\
Period (P) & 3 & 0.632 & 40.91 & $9.11^{*}$ & $11.35^{*}$ & 36.80 & $30.15^{*}$ & $16.75^{*}$ & $9.01^{*}$ & 86.32 \\
P* Species & 3 & 2.736 & $17.04^{*}$ & $4.11^{*}$ & $4.76^{*}$ & $28.00^{*}$ & $19.27^{*}$ & $11.46^{*}$ & $3.71^{*}$ & 40.67 \\
Residual & 98 & 1.094 & 3.6 & 0.60 & 0.84 & 3.33 & 3.28 & 2.77 & 1.07 & 25.16 \\
\hline
\end{tabular}

$* \mathrm{p}<0.05$

$\mathrm{SV}=$ Sources of variation; $\mathrm{Sp}=$ Species $; \mathrm{S}=$ Seasons of birth; $\mathrm{P}=$ Periods of birth; $\mathrm{df}=$ Degrees of freedom; $\mathrm{S}$. Vol. $=\mathrm{Semen}$ volume $(\mathrm{ml}) ; \mathrm{AD}=\mathrm{Age}$ at disposal (d); AFSC = Age at first semen collection (d); AFSF = Age at first semen freezing (d); FSPP = Frozen semen production period $(\mathrm{d})$; SPP = Semen production period (d); ALSC $=$ Age at last semen collection (d); ALSF $=$ Age at last semen freezing (d) and IM = Initial motility. 
Table 7. Least squares mean \pm SE for semen volume semen volume, age at disposal, age at first semen collection, age at first semen freezing, frozen semen production period, semen production period, age at last semen collection, age at last semen freezing and initial motility for different periods

\begin{tabular}{lcccr}
\hline Traits & Period 1 & Period 2 & Period 3 & Period 4 \\
\hline Semen volume & $5.89^{\mathrm{NS}} \pm 0.308$ & $5.62^{\mathrm{NS}} \pm 0.201$ & $5.66^{\mathrm{NS}} \pm 0.200$ & $5.44^{\mathrm{NS}} \pm 0.203$ \\
AFSC & $1,361.3^{\mathrm{a}} \pm 72.6$ & $977.8^{\mathrm{b}} \pm 47.5$ & $843.5^{\mathrm{c}} \pm 47.1$ & $861.2^{\mathrm{bc}} \pm 47.9$ \\
AFSF & $1,517.2^{\mathrm{a}} \pm 85.5$ & $1,179.5^{\mathrm{b}} \pm 55.9$ & $940.6^{\mathrm{c}} \pm 55.4$ & $1,007.0^{\mathrm{c}} \pm 56.4$ \\
FSPP & $826.1^{\mathrm{a}} \pm 96.8$ & $801.6^{\mathrm{a}} \pm 63.2$ & $580.7^{\mathrm{b}} \pm 63.2$ & $393.8^{\mathrm{c}} \pm 69.5$ \\
SPP & $1,227.1^{\mathrm{a}} \pm 155.7$ & $1,383.5^{\mathrm{ac}} \pm 101.5$ & $1,039.7^{\mathrm{bcd}} \pm 101.5$ & $770.1^{\mathrm{d}} \pm 111.8$ \\
AD & $2,761.80^{\mathrm{a}} \pm 177.1$ & $2,636.4^{\mathrm{a}} \pm 115.5$ & $2,184.6^{\mathrm{b}} \pm 115.5$ & $1,798.3^{\mathrm{c}} \pm 127.1$ \\
ALSC & $2,590.1^{\mathrm{a}} \pm 170.7$ & $2,426.7^{\mathrm{a}} \pm 111.3$ & $1,923.5^{\mathrm{b}} \pm 111.3$ & $1,684.1^{\mathrm{b}} \pm 122.5$ \\
ALSF & $2,629.3^{\mathrm{a}} \pm 169.2$ & $2,382.5^{\mathrm{a}} \pm 110.4$ & $1,966.5^{\mathrm{b}} \pm 110.3$ & $1,759.1^{\mathrm{b}} \pm 121.5$ \\
Initial motility & $58.2^{\mathrm{NS}} \pm 0.1$ & $64.9^{\mathrm{NS}} \pm 0.0$ & $66.1^{\mathrm{NS}} \pm 1.0$ & $64.6^{\mathrm{NS}} \pm 0.0$ \\
\hline
\end{tabular}

$* \mathrm{p}<0.05$.

S. Vol. $=$ Semen volume $(\mathrm{ml}) ;$ AFSC $=$ Age at first semen collection $(\mathrm{d}) ;$ AFSF $=$ Age at first semen freezing $(\mathrm{d}) ; \mathrm{FSPP}=$ Frozen semen production period (d); SPP = Semen production period (d); AD = Age at disposal (d); ALSC = Age at last semen collection (d) and ALSF = Age at last semen freezing (d). Period 1 = 1999 to 1990; Period 2 = 1991 to 1996; Period 3 = 1997 to 2002; Period $4=2003$ to 2010.

a, b,c,d Rows with no common superscript indicates non-significant difference between the values $(\mathrm{p}<0.05)$.

value on early puberty, larger testis size, and increased sperm production by individual bulls (Casas et al., 2007). The initial selection of the male calves has no impact on the reproductive potential of the future bulls. One of the remarkable observations in this regard is that higher frequency of subfertility in the cattle among the dairy breeding bulls. Concurrently, the freezable semen production capacity was also less in crossbred cattle. Earlier reports also show that the seminal parameters are poor in crossbred bulls than the indigenous breeds (Sethi et al., 1989; Rao et al., 1995; Khate, 2005; Mukhopadhyay et al., 2011). In a study on 173 Frieswal bulls at PDC, Meerut, India, Tyagi et al. (2000) found that $54.91 \%$ and $45.09 \%$ of the crossbred bulls produced semen of poor quality and poor freezability, respectively. This account was much higher than our observation at GADVASU herd. Available reports show that about $50 \%$ of the crossbred bulls produce semen which is not cryopreservable (Sethi et al., 1989; Bhavsar, 1993; Sahni and Mohan, 1998). Variations in spermatozoal resistance to hypertonic solutions may affect

Table 8. Regression coefficient $\left(b_{o}, b_{I}\right)$ and coefficient of determination $\left(\mathrm{R}^{2}\right)$ along with respective probability values for different male reproduction parameters using AFSC as the dependent variable in crossbred cattle

\begin{tabular}{lcccrcc}
\hline SN & DV & IV & $\mathrm{R}^{2}(\%)$ & \multicolumn{1}{c}{$\mathrm{b}_{\mathrm{o}}$} & \multicolumn{1}{c}{$\mathrm{b}_{\mathrm{I}}$} & $\mathrm{P}$ \\
\hline 1 & SPP & AFSC & 23.5 & 557.55 & 0.695 & 0.00 \\
2 & AFSF & AFSC & 64.5 & 213.46 & 0.998 & 0.00 \\
3 & AD & AFSC & 57.9 & 859.28 & 1.533 & 0.00 \\
4 & FSPP & AFSC & 20.8 & 491.93 & 0.596 & 0.00 \\
5 & IM & AFSC & 3.4 & 55.85 & -0.003 & 0.19 \\
\hline
\end{tabular}

SPP $=$ Semen production period $;$ AFSF $=$ Age at first semen freezing; $\mathrm{AD}$ = Age at disposal; FSPP = Frozen semen production period; $\mathrm{IM}=$ Initial motility; DV = Dependent variable; IV = Independent variable; $b_{0}=$ Intercept constant; $b_{I}=$ Regression coefficient; $R^{2}=$ Coefficient of determination and $\mathrm{P}=$ Probability of rejecting the regression model. the differential cryopreservability of different bulls (Maule, 1962; Tyagi et al., 2000). Increase in exotic inheritance may improve the freezability of crossbred semen (Methew et al., 1982).

\section{Incidence of subfertility}

The present investigation shows that the significantly important cause of disposal of breeding bulls is subfertility $(\mathrm{p}<0.05)$. Due to sub-optimal reproductive efficiency almost half to one-third of the reserved stock has been disposed. A number of reports related to the vital records on semen production parameters and bull wastage (Aehnelt et al., 1963; Walter and Weiser, 1966; Djimde and Weniger, 1984) specify that infertility and subfertility are the major reasons for disposal of breeding bulls of dairy animals in the tropical and temperate countries (Mukhopadhyay et al., 2011). The major reasons for disposal of breeding bulls are the poor semen quality in crossbred and Murrah buffaloes (Suryaprakasam and Rao, 1993) and the poor semen freezability in case of exotic and crossbred bulls (Mathew et

Table 9. Regression coefficient (bo, $b_{1}$ ) and coefficient of determination $\left(\mathrm{R}^{2}\right)$ along with respective probability values for different male reproduction parameters using AFSC as the dependent variable in Murrah buffalo

\begin{tabular}{lccrrrc}
\hline SN & DV & IV & $\mathrm{R}^{2} \%$ & \multicolumn{1}{c}{$\mathrm{b}_{\mathrm{o}}$} & \multicolumn{1}{c}{$\mathrm{b}_{1}$} & $\mathrm{P}$ \\
\hline 1 & SPP & AFSC & 1.1 & $1,393.84$ & -0.245 & 0.455 \\
2 & AFSF & AFSC & 49.9 & 494.84 & 0.616 & 0.000 \\
3 & AD & AFSC & 1.4 & $2,190.35$ & 0.306 & 0.383 \\
4 & FSPP & AFSC & 0.05 & 268.30 & -0.039 & 0.622 \\
5 & IM & AFSC & 10.5 & 61.81 & -0.007 & 0.013 \\
\hline
\end{tabular}

SPP $=$ Semen production period; AFSF $=$ Age at first semen freezing; $\mathrm{AD}$ $=$ Age at disposal; FSPP = Frozen semen production period; IM = Initial motility; DV = Dependent variable; IV = Independent variable; $b_{0}=$ Intercept constant; $b_{1}=$ Regression coefficient; $R^{2}=$ Coefficient of determination and $\mathrm{P}=$ Probability of rejecting the regression model. 
al., 1982; Suryaprakasam and Rao, 1993). Roman et al. (1968) indicated that reproductive incompetence and failure to serve accounted for $47 \%$ and $16 \%$, respectively, of all reasons of disposal of beef sires in US and Canada during 1949 to 1964 . While in India, the most prevalent reasons given for culling of 469 bulls (at three AI centers in Kerala, India) were poor semen quality $(45.42 \%)$, poor libido $(36.46 \%)$, attainment of production targets (14.07\%) and poor semen freezability $(10.87 \%$ ) (Sudheer and Xavier, 2000). This becomes a cause for huge wastage and consequently results in huge economic losses, as these bulls are discarded at around 2 to 3 years of age. Apart from this, there is also a reduction in the genetic gain due to disposal of bulls selected for breeding purpose. Often, even the bulls with good libido and producing freezable semen, they tend to produce low grade ejaculates under stressful conditions (Bhakat et al., 2009). Kodagali et al. (1980) reported that very high proportion (i.e. $23.81 \%$ and $38.09 \%$ ) of Surti buffalo bulls (at Amul AI centers, India) were culled due to poor semen quality and overall sexual derangements, respectively, while the occurrence of poor libido was only $2.38 \%$, during the four years tenure at Anand, Gujarat, India. A total of 1 case of cryptorchidism was recorded in cattle bull in the present study, whereas no such cases were found in buffalo bull. Collection of semen with artificial vagina is very challenging when the bulls suffer from penile deviation; in our case two cattle bulls with penile deviation but acceptable seminal profile were thus culled.

\section{Factors affecting the reproductive parameters of dairy bulls}

Season of birth bears its effect up to few months of age of the animal and gradually fades away. In the present study, the seasons of birth didn't differ significantly for any of the seminal parameters, however, in a study on buffalo, the male calves born during spring season were found to have higher culling rate (Kodagali et al., 1980). Effects of period of birth and species $\times$ period interaction are entirely herd specific. In the present context improvement over the period has been noted for almost all the parameters. Most reproductive traits are heavily influenced by differences in herd management practices and other environmental factors. Better managemental practices and regular monitoring of reproductive health have contributed to improvement of the reproductive parameters. Wilcox et al. (1966) found that the periods were affecting the semen production parameters significantly, while analyzing the data on 3,774 males of US and Canada. Sethi et al. (1989) concluded that bulls donating larger volume of neat semen with higher mass activity are supposed to produce freezable semen. The mean age of first semen collection (AFSC) and freezing (AFSF) were lower in cattle since these are crossbred, hence attain maturity earlier than buffalo bulls. The maximum herd life of the buffalo bulls, as evident from the mean Age at disposal (AD), is explained by the delayed initiation of semen donation and freezable semen production. Our findings on the mean age at first semen collection in buffalo are lesser than what was reported for Murrah bulls by Suryaprakasham and Rao (1993) but comparable to Sahiwal and crossbred bulls as reported by the above authors and Rao (1995) on Jersey $\times$ Ongole crossbred and Ongole bulls. Average age of first semen donation could be reduced by subjecting the bulls on training at an early age, without affecting the semen quality and freezability (Sethi et al., 1989). The age of starting semen donation is lower in crossbred than indigenous humped breed of cattle (Mukhopadhyay et al., 2010). The results in our study have revealed a lower breeding period of the buffalo bulls than the findings of Rao et al. (1995) and Sudheer and Xavier (2000) in various indigenous and crossbred bulls in other herds. Kodagali et al. (1980), while studying the culling percentage of Surti buffalo bulls, reported the mean age at disposal (AD) and breeding tenure as 2,330 and $480 \mathrm{~d}$, respectively. Mathur et al. (2002) observed that there was no significant seasonal difference in mass motility, progressive motility and sperm concentration except for semen volume, which was the lowest during winter (3.84 vs $4.17,4.18 \mathrm{ml}$ ), as compared to summer and rainy seasons in Frieswal bulls.

\section{Prediction of semen production parameters}

The coefficient of determination $\left(\mathrm{R}^{2}\right)$ of the regression equation is equal to $50 \%$ in case of buffalo (for AFSF) and more than $50 \%$ in case of cattle (for AFSF and AD). This indicates that the AFSF and AD can be predicted by AFSC. To the best of our knowledge, no such prediction equations have been constructed to foresee the possible herd-life (i.e. age at disposal) of the cattle bulls. This warrants further investigation using more number of animals in order to validate the prediction equation.

\section{IMPLICATIONS}

Subfertility problems like, inadequate sex drive and unacceptable seminal profile were the significant reasons for culling of the breeding. Semen donation parameters, like age at first semen collection, age at first semen freezing were significantly higher in buffalo bulls. Our study reveals that the occurrence of subfertility problem is at par in crossbred cattle and buffalo bulls. The present study clearly demonstrates that there exists a variation in reproductive parameters in the bovine bulls, which could be studied at the molecular level to unveil any genomic markers associated with subfertility and/or infertility. The bulls may be utilized to obtain semen by subjecting the young bulls to training at an early age, thereby decreasing the initial age of 
semen donation.

\section{ACKNOWLEDGEMENTS}

The research work has been conducted with the funds provided in the RKVY scheme (Government of India).

\section{REFERENCES}

Aehnelt, E., J. Hahn and J. K. Dittmar. 1963. Causes for and age at culling in A.I. bulls with special reference to the longevity of their dams and granddames. Tierärztl. Umsch. 18:408-416.

Álvarez, C., J. A. Castilla, L. Martínez, J. P. Ramírez, F. Vergara and J. J. Gaforio. 2003. Biological variation of seminal parameters in healthy subjects. Hum. Reprod. 18:2082-2088.

Bhakat, M., T. K. Mohanty, A. K. Gupta and V. S. Raina. 2009. Effect of season and management on semen quality of breeding bulls- A review. Agric. Rev. 30:79-93.

Bhavsar, B. K. 1993. Perspective and prospective of the role of artificial insemination and gynecology in enhancing livestock production. Indian J. Anim. Reprod. 14:66-68.

Daskin, A., N. Yurdaydin and T. Ozdemir. 1998. Effects of cryptorchidism on spermatological properties. J. Lalahan Livest. Res. Ins. (Turkey) 381:79-84.

Djimde, M. and J. H. Weniger. 1984. Semen quality of bulls in relation to breeding groups and seasons in Bangladesh. Zeitscrift-fur-Tierzuchtung-und-zuchtungsbiologie. 101:59-69.

Casas, E., D. D. Lunstra, L. V. Cundiff and J. J. Ford. 2007. Growth and pubertal development of $\mathrm{F}_{1}$ bulls from Hereford, Angus, Norwegian Red, Swedish Red and White, Friesian, and Wagyu sires. J. Anim. Sci. 85:2904-2909.

Khate, K. 2005. Studies on multistage selection of dairy bulls. M.V.Sc. Thesis, National Dairy Research Institute. Karnal, Haryana, India.

Kodagali, S. V., B. K. Bhavsar and F. S. Kavani. 1980. Age at and reasons of disposal of A.I. buffalo bulls. Indian J. Anim. Health. 19:31-34.

Mathew, A., P. J. Joseph and T. K. Jose. 1982. Semen characteristics of purebred and crossbred bulls. Indian Vet. J. 59:364-367.

Mathur, A. K., S. Tyagi and S. P. Singh. 2002. Frieswal bull- an experience of HF with Sahiwal. Saras J. Livest. Poult. Prod. 181:21-23.
Maule, J. P. 1962. Ultra low temperature storage of semen. The semen of animals and artificial insemination. In: Technical Communication number 15 of Commonwealth Bureau of Animal Breeding and Genetics (Ed. C. A. B. Bucks) Edinburgh, England.

Mukhopadhyay, C. S., A. K. Gupta, B. R. Yadav, K. Khate, V. S. Raina, T. K. Mohanty and P. P. Dubey. 2010. Subfertility in males: an important cause of bull disposal in bovines. AsianAust. J. Anim. Sci. 23:450-455.

Mukhopadhyay, C. S., A. K. Gupta, B. R. Yadav, A. Gupta, T. K. Mohanty and V. S. Raina. 2011. Study on the effect of various uncompensable traits on fertilizing potential in cattle and buffalo bulls. Livest. Sci. 136:114-121.

Rao, C. V. and A. V. N. Rao. 1995. Puberty and semen production period in breeding bulls. Indian Vet. J. 72:885-886.

Rao, K. R., O. Sremanarayana and R. Mukundarao. 1995. Breeding life and disposal patterns of breeding bulls. Indian Vet. J. 72:883-884.

Roman, J., C. J. Wilcox, R. B. Becker and M. Koger. 1968. Tenure and reasons of disposal of artificial insemination dairy sires. J. Dairy Sci. 52:1063-1069.

Sahni, K. L. and G. Mohan. 1998. Annual report of animal reproduction division. Indian Veterinary Research Institute. Izatnagar, U.P.

Sethi, R. K., V. S. Raina, B. K. Joshi and M. Gurnani. 1989. Multistage selection of crossbred males and effect of their age and body weight on semen quality and freezability. Indian J. Anim. Sci. 59:171-174.

Snedecor, G. W. and W. G. Cochran. 1994. Statistical Methods. $8^{\text {th }}$ Ed. Iowa State University Press, Ames, Iowa, USA.

Sudheer, S. and C. J. Xavier. 2000. Disposal pattern of breeding bulls in Kerala. Indian J. Anim. Reprod. 211:72-73.

Suryaprakasam, T. B. and A. V. N. Rao. 1993. Studies on breeding life and disposal pattern of AI sires in Andhra Pradesh. Indian Vet. J. 70:1022-1024.

Tyagi, S., A. K. Mathur and S. C. Agarwal. 2000. Semen production performance of Frieswal bulls. Indian J. Anim. Reprod. 70:1032-1034.

Walter, F. and K. Weisser. 1966. Reasons for wastage of bulls at an AI center. Terzücht. 20:72.

Wilcox, C. J., J. Roman and R. B. Becker. 1966. Fate of young sires used for artificial insemination. J. Dairy Sci. 50:884-886. 